\title{
Assessing the operations of commuter rail: A case study in KRL commuter line of Jakarta Metropolitan Area
}

\author{
$M M$ Ulkhaq $^{*}, A K$ Widodo, $N$ Izati, $S Y$ Santoso, $W H W M$ Sutrimo, and \\ $P$ Y Akshinta \\ Department of Industrial Engineering, Diponegoro University, Semarang, Indonesia
}

\begin{abstract}
Public transportation is considered to be able to handle several transportation problems, such as "the ancient" traffic congestion to "the contemporary" environmental impact. Rail transit, or also known as commuter rail, is one of the most important public transportation types since it could reduce effectively the traffic congestion. At this instant, service quality of commuter rail is essential to achieve the customer satisfaction. This research aims to assess the operations of commuter rail by assessing its service quality. The importance-performance and gap analysis (IPGA) based on nine criteria was applied to accomplish the objective. A case study was conducted in KRL commuter line of Jakarta Metropolitan Area which is operated by P.T. Kereta Commuter Indonesia. The result shows that the safety criterion has the highest relative importance score and the fare has the highest relative performance score. The IPGA technique then was employed to build strategies based on the relative importance and performance from the passengers' point of view.
\end{abstract}

\section{Introduction}

Transportation is believed to be able to influence the growth of the city and its livability since it enables trade between people, which is essential for the development of civilizations. The larger the city, the greater its complexity and the potential for disruptions, particularly when the complexity is not effectively managed. The most important transportation challenges are often related to urban areas and take place when transportation systems cannot satisfy the several requirements of urban mobility.

Urban productivity is highly interrelated with the efficiency of its transportation system to move labor, consumers, and freight between multiple origins and destinations. In addition, transport terminals such as ports, airports, and railyards are located within urban areas, contributing to a specific array of problems. They are traffic congestion, long commutes, urban freight distribution, and environmental impacts. Public transportation is considered as an effective solution to some of those mobility issues. It also plays a crucial role in the social and environmental dimensions. It improves access to workplaces and infrastructures while enabling positive environmental effects with a potential reduction in

*Corresponding author: ulkhaq@live.undip.ac.id 
green-house gas emissions [1]. Thus, it provides an alternative to private car as a major transportation mode.

Rail transit, or commuter rail, has been considered as one of the most important public transportation types, see for example [2]-[4]. The commuter rail could help reduce the traffic congestion in three ways. First, it can reduce travel time for passengers who shift modes. Even though there is no time saving, perceived cost is less than driving if the rail transit service is comfortable. Second, grade-separated rail transit decreases delays on parallel roadways. Third, rail transit can stimulate people to drive less and walk if they live in more automobile-dependent neighborhoods [5]. At this point, the quality of transportation alternatives plays an important role. If the quality of alternatives is lesser, car drivers will be more unwilling to shift modes - as a consequence, more congestion will occur. Therefore, improving service quality of commuter rail could reduce the number of car trips, which benefits all passengers.

Quality of service is a central concern for public transport users, transport operators, as well as transport authorities [6]. In addition, good public transport service quality remains an elusive dream for many cities and communities [7]. However, assessing the quality of service is a challenging task due to the nature of the service, which is intangible, simultaneous, inseparable, and heterogeneous [8]. In fact, ensuring a high customer satisfaction level through the excellent service quality is an essential task for managers and authorities. Therefore, determining the efficiency and satisfactory levels of the services are needed to be assessed by the service providers [9].

This research attempted to assess the operations of the commuter line by evaluating its service quality. The importance-performance and gap analysis (IPGA) [10] using nine criteria with 26 sub-criteria [11] is utilized to accomplish this objective (see Section 2). A case study was conducted in KRL Commuter Line of Jakarta Metropolitan Area. As the capital and the largest city in Indonesia, Jakarta has the longest rail network. The commuter operated in Jakarta is known as KRL (or Kereta Rel Listrik in Bahasa Indonesia). This research can be used to evaluate the economic performances, to connect the service provider's achievements and difficulties that are faced, as well as to improve the service quality.

\section{Research Methods}

In this research, the criteria for assessing the operations of the commuter rail were determined as nine criteria with consist of 26 sub-criteria [11]. The first criterion is train comfort (TC). A passenger's comfort during the time he/she spends during a journey is evaluated through four sub-criteria, i.e., level of crowdedness and density in the trains (TC1), cleanliness of inside the trains (TC2), noise level and vibration level during the journey (TC3), and air conditioning system inside the trains (temperature and humidity) (TC4). This comfort criterion has been used as a criterion to evaluate customer satisfaction for rail transit passengers, see for example [12]-[14].

The second criterion is ticketing (TT). It is believed that better ticketing system could decrease the loading time and eventually decrease the travel time. This criterion comprises of two sub-criteria, i.e., ticketing system (TT1) and vending machines/services (TT2). The third criterion is information systems (IS). It is evaluated through six sub-criteria, i.e., the usage of modern equipment in station services, such as, screen display for schedule, train departures, and routes [12] (IS1), the usage of modern equipment inside the train services, such as, screen display for route map(s) (IS2), announcements in stations during and after breakdowns (IS3), announcements in trains during and after breakdowns (IS4), up-todatedness of the website (IS5), and service provided by phone services (IS6). 
The fourth criterion is accessibility (AC). It is assessed based on three sub-criteria, i.e., access to metro stations (AC1), access and condition of escalators, elevators, and belt conveyors (AC2), and the smooth functioning of the tollgates (AC3). This criterion is considered as a very important criterion in the evaluation of customer satisfaction for public transportation [12], [14]. The fifth criterion is safety (SF). It comprises of two sub-criteria, i.e., safety inside the stations (SF1) and safety inside the trains (SF2). The sixth criterion is station comfort (SC). It respects to three sub-criteria, as cleanliness of the stations (SC1), lighting of the stations (SC2), and comfort level in the stations (SC3). The station comfort is very important for the passengers [15]-[17] because they should feel comforted and relaxed before train departures especially before long runs. Cleaner, better lighted, and comforter seats at stations provide passengers to relax.

The seventh criterion is welcoming (WC). Attitudes and behaviors of the security and other crew toward passengers have a higher effect on the users' perception of the quality of the service provided. Welcoming, which is identified as one of the most important criterion for customer satisfaction in rail transit services [16], [17], only consists of one sub-criterion, i.e., attitude and behaviors of the security staff (WC1). The eight criterion is fare (FR). Costliness of commuter tickets (FR1) and interchanges (switching trains or mode) (FR2) are considered as sub-criteria in this criterion. This criterion can be considered as a pricequality ratio and it values the quality of the service by comparing the price based on the perceptions of the passengers. The last is time (TM). This criterion includes three subcriteria, i.e., waiting time for the commuter before departure (TM1) [12], [13], [18], journey time (TM2) [13], [18], and arrival performance of the trains with respect to schedules (TM3) [18].

These 26 sub-criteria are then used to analyze the performance of the object of the research. The relative importance of each sub-criterion along with its corresponding relative performance are employed to establish the IPGA grid. The IPGA has been shown that the gap analysis model is not only able to be the referential basis of improving service quality, but can also be regarded as the key index of expanding the traditional importanceperformance analysis (IPA). Although the IPA is widely implemented (see for example [19]-[21]), it has been criticized for several reasons ([22], [23]).

Similar with the IPA model, the IPGA is a two-dimensional state space where the vertical axis described the relative importance of the attributes, while the horizontal axis described the relative performance (how well the service provider is performing the service). The IPGA's two-dimensional state space was then categorized into four quadrants: concentrate here, keep up with the good work, low priority, and possible overkill. The intersection of two coordinate axes of the matrix will be the critical point that influences the strategic planning of resources distribution.

The first quadrant, i.e., concentrate here, which is located in the north-west corner, has the sub-criteria that become the priority of the management due to having high relative importance but indicates low relative performance. It indicates that a negative gap existed between the performance and importance. The second quadrant, namely, keep up with the good work, identified that both relative importance and performance of the customers already highly rated and should be maintained well by the management. Sub-criteria that are rated low in both relative importance and performance are put in the third quadrant, i.e., low priority, which is located in the south-west corner. The last is possibly overkill, where there are unnecessary sub-criteria due to having less relative importance ratings but excellent relative performance. Thus, there might be no good reason to improve these subcriteria.

The coordinate of each point is determined by the relative importance of $j$ th subcriterion $R I(j)$ as the vertical axis and the relative performance of $j$ th sub-criterion $R P(j)$ as the horizontal axis. Detail description and formula for each notation can be found in [10]. 


\section{Case Study}

The objective of this research is to assess the operations of the commuter line using the IPGA [10]. The object of this research was KRL Commuter Line which is operated in Jakarta Metropolitan Area, the capital and the largest city in Indonesia. The KRL is not only operated in Jakarta, but also to the satellite city of Jakarta, such as Depok, Bogor, Bekasi, Tangerang, and South Tangerang. It is operated by P.T. Kereta Commuter Indonesia, a subsidiary of P.T. Kereta Api Indonesia (KAI), a national railway company. The infrastructures are owned by KAI, yet some of the stations and lines are shared with intercity trains. The network has 80 stations with 6 lines, namely Jakarta-Bogor, JatinegaraBogor, Tanah abang-Rangkasbitung, Jakarta-Cikarang, Duri-Tangerang, and JakartaTanjung Priok [24].

The participants of this survey were required to have experiences in using the service of the commuter. The potential participants were first approached and asked if they agree to participate in the survey. All item statements were measured on a 5-point Likert-type scale, ranging from 1 (strongly disagree for performance-type-and unimportant for importancetype questionnaire) to 5 (strongly agree for performance-type-and important for importance-type questionnaire). One hundred and seventy-five respondents participated in this survey. They consist of students, employees, entrepreneurs, etc., indicates plenty diversity for the purpose of the research.

The reliability test with Cronbach's alpha [25] was conducted to verify if the respondents' answers to any questions tend to relate one and another. The results are shown in table 1. Note that all of the dimensions have the value of Cronbach's alpha more than 0.6, indicated that the questionnaire being utilized is reliable [26]. The relative importance scores of each sub-criterion are shown in table 2.

Table 1. The Cronbach's alpha scores for each criterion.

\begin{tabular}{|l|c|c|}
\hline \multicolumn{1}{|c|}{ Criteria } & Number of sub-criteria & The Cronbach's alpha \\
\hline Train comfort & 4 & 0.661 \\
\hline Ticketing & 2 & 0.620 \\
\hline Information system & 6 & 0.847 \\
\hline Accessibility & 3 & 0.674 \\
\hline Safety & 2 & 0.733 \\
\hline Station comfort & 3 & 0.800 \\
\hline Welcoming & 1 & N/A \\
\hline Fare & 2 & 0.696 \\
\hline Time & 3 & 0.891 \\
\hline
\end{tabular}

Table 2. The result of the case study.

\begin{tabular}{|c|c|c|c|l|c|c|c|}
\hline Criteria & Sub-criteria & $\mathrm{RP}(j)$ & $R I(j)$ & Criteria & Sub-criteria & $\mathrm{RP}(j)$ & $\mathrm{RI}(j)$ \\
\hline \multirow{4}{*}{ Train comfort } & TC1 & -1.331 & 0.959 & \multirow{2}{*}{ Accessi- } & AC1 & -1.039 & 0.979 \\
& TC2 & -0.941 & 1.095 & AC2 & -1.079 & 0.872 \\
& TC3 & -1.064 & 0.882 & bility & AC3 & -0.912 & 1.039 \\
& TC4 & -0.988 & 1.001 & & SF1 & -1.036 & 1.110 \\
\hline \multirow{2}{*}{ Ticketing } & TT1 & -0.939 & 1.020 & Station & SF2 & -1.043 & 1.117 \\
& TT2 & -1.002 & 0.939 & & SC1 & -0.955 & 1.080 \\
\hline \multirow{3}{*}{ Informatio } & IS1 & -0.983 & 1.027 & & SC2 & -0.927 & 1.025 \\
system & IS2 & -0.970 & 1.011 & Comfort & SC3 & -0.992 & 1.100 \\
& IS3 & -0.921 & 1.074 & Fare Time & FR1 & -0.859 & 1.011 \\
& IS4 & -0.917 & 1.055 & & FR2 & 1.009 & 0.547 \\
\hline
\end{tabular}




\begin{tabular}{|l|c|c|c|c|c|c|c|}
\hline & IS5 & -1.052 & 1.016 & & TM1 & -1.120 & 0.956 \\
& IS6 & -1.019 & 0.939 & & TM2 & -1.089 & 0.997 \\
\hline Welcoming & WC1 & -0.942 & 1.053 & & TM3 & -1.081 & 1.096 \\
\hline
\end{tabular}

The highest average score is obtained by the safety criterion with 1.114 . It seems that the respondents thought that this criterion is the most important factor in assessing the operations of the commuter line. Most of passengers feel that the staff need to improve the safety guiding, including safety guidelines entrance direction, point passenger misconduct, and take care of things. In addition, the commuter line construction and management need to be strengthened and improved, including emergency equipment demonstrations, emergency first aid measures, emergency accident exercises, safety signs strengthening, and safety personnel patrol. On the other hand, the fare criterion has the lowest score with 0.779. It seems that the passengers do not consider much about the cost of the transportation.

The scores for relative performance are also shown in table 2. All of the criterion have the negative average values, except for the fare criterion, i.e., 0.075 , as the best criterion among others. It indicates the passengers think that the transportation mode has the "best price" for them. As a developing country, the management is believed that the price is considered as one of the most important aspect in people's life in Indonesia; thus, the firm sees this matter as a concern, resulting in customers' satisfaction of the price of the commuter line. Contrarily, the lowest score of the relative performance is gained by the time criterion with -1.097. It indicates that the customers are not satisfied about how the company manages the waiting time as well as the journey time.

Since most of the criterion have the negative values, indicating that the company is lack of capability for providing the best service for the customers and has to do something in order to achieve the customer satisfaction. The IPGA technique can be employed to build some strategies based on the relative importance and performance from the passengers' point of view. The average score for each sub-criterion are plotted in the two-dimensional state space, see figure 1 .

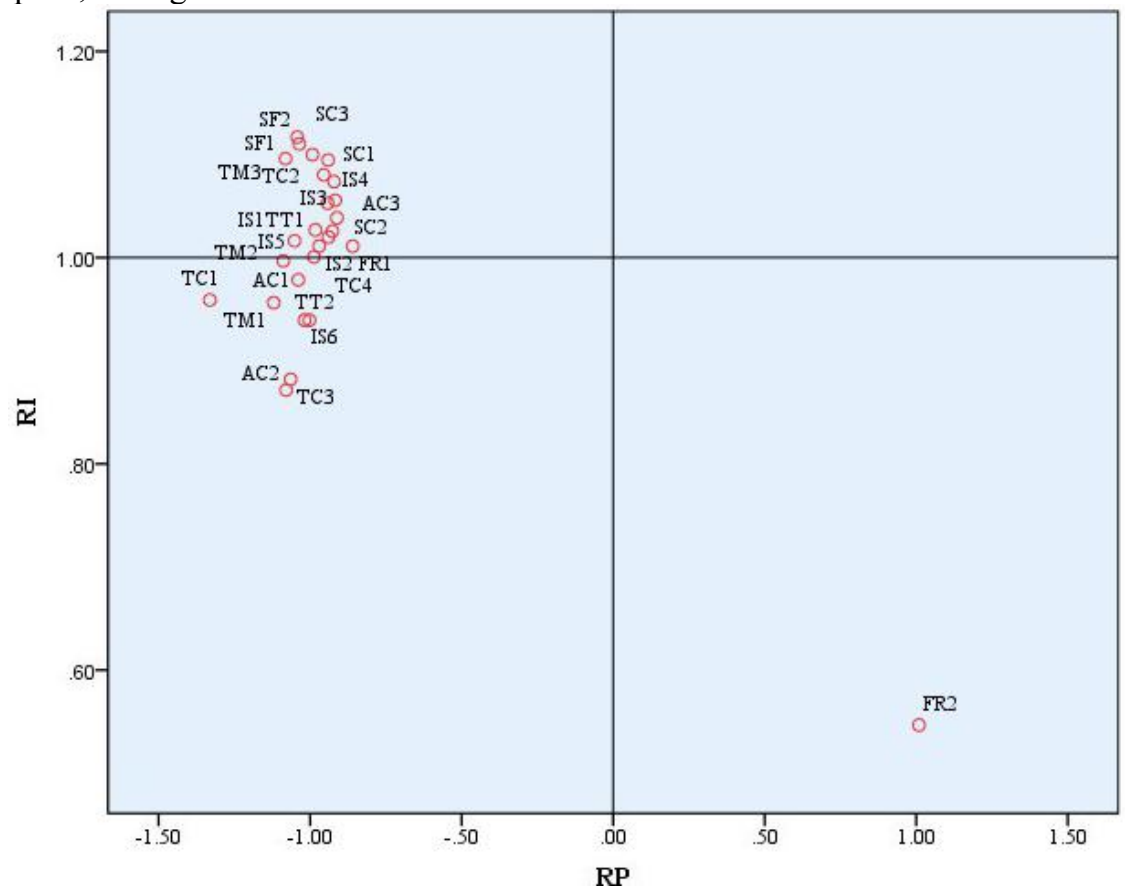

Fig. 1. The IPGA grid of the case study's result. 
Based on the result of the IPGA grid, there are only one sub-criterion which is in the "possible overkill" quadrant, 8 sub-criteria which are positioned in the "low priority" quadrant, and 17 sub-criteria that are located in the "concentrate here" quadrant. The subcriterion that is located in possible overkill quadrant possess low relative importance and high relative performance, i.e., FR2 sub-criterion. The 8 sub-criteria that are inside the low priority quadrant are considered less important and also have low relative performance scores. They are TC1, TC3, TT2, IS6, AC1, AC2, TM1, and TM2. The rest of the subcriteria are concentrated in the concentrate here quadrant. They are the ones with low relative performance but importantly perceived by the customers; thus, they should receive the most investment to boost the customers' satisfaction since it will bring the maximum effect with the minimum investment.

\section{Conclusion \& Future Research Direction}

This paper has demonstrated the assessment of service quality using the IPGA [10]. A case study was managed in KRL Commuter Line of Jakarta Metropolitan Area, based on nine criteria with 26 sub-criteria. The IPGA which consists of relative importance and performance aspects has been found to provide a relative simple and inexpensive means of doing service quality assessment.

The result (see Section 3) shows that the assessment has many potential benefits for the management of the company. Identifying passengers' perceptions toward the relative performance and importance allows management to better personalize its marketing efforts to ensure the expectation of the passengers are met. This includes identifying, prioritizing, and improving areas of service weakness and ensuring that valuable resources are allocated in the most effective areas.

For the future research, it is suggested to apply the customer zone of tolerance-based service quality (CZSQ) and CZSQ-based IPA (CZIPA) [27] to assess the service quality based on the competitive zone of tolerance by benchmarking against its competitors and to prioritize the service attributes to be improved. Although this novel method is originally developed in the area of hospitality, it can be further implemented to assess the service quality of the commuter line with some adjustments and modifications. However, despite of the superiority of CZSQ and CZIPA, the applications remain limited-one modification of these methods in the area of airline service that could be worthy to be mentioned perhaps the work by [28].

\section{References}

1. Dubé J, Thériault M and des Rosiers F 2013 Transport. Res. A-Pol. 54 49-66

2. Givoni M and Banister D 2012 J. Transp. Geogr. 22 306-307

3. Özgür Ö 2011 Transp. Policy 18 147-155

4. Scherer M 2010 Transport. Res. Rec.: J. Transport. Res. Board 2144 11-19

5. Litman T 2007 Transp. Policy 14 94-97

6. Aguiléra V, Allio S, Benezech V, Combes F and Milion C 2014 Transport. Res CEmer. 43 198-211

7. Too L and Earl G 2010 Sust. Dev. 18 51-61

8. Fitzsimmons J A, Fitzsimmons M J and Bordoloi S 2014 Service Management: Operations, Strategy, and Information Technology 8th ed (New York, NY: McGrawHill) 
9. Hassan M N, Hawas Y E and Ahmed K 2013 Transport. Res. A-Pol. 50 47-61

10. Lin S P, Chan Y H and Tsai M C 2009 Total Qual. Manag. Bus. 20 829-846

11. Aydin N, Celik E and Gumus A T 2015 Transport. Res. A-Pol. 77 61-81

12. Nathanail E 2008 Transport. Res. A-Pol. 42 48-66

13. Brons M, Givoni M and Rietveld P 2009 Transport. Res. A-Pol. 43 136-149

14. Eboli L and Mazzulla G 2011 Transp. Policy 18 172-181

15. Eboli L and Mazzulla G 2012 Procedia Soc. Behav. Sci. 54 96-106

16. de Oña R, Eboli L and Mazzulla G 2014 Transport 29 75-83

17. de Oña J, de Oña R, Eboli L and Mazzulla G 2015 Int. J. Sustain. Transp. 9 612-626

18. E. Cascetta and A. Cartenì 2014 Int. J. Sustain. Transp. 8 84-106

19. Pramono S N W, Ulkhaq M M, Trianto R, Rasyida D R, Setyorini N A, Setiowati P R and Jauhari W A 2017 AIP Conference Proceedings 1902020035

20. Ulkhaq M M, Wijayanti W R, Kusumawati A, Aulia F S, Wijayanti R S and Wiganingrum R 2017 Proc. Int. Conf. on Indus. Eng. and App. (Nagoya) vol 4 (IEEE Xplore) pp 146-150

21. Rasyida D R, Ulkhaq M M, Setiowati P R and Setyorini N A 2016 MATEC Web of Conferences $\mathbf{6 8} 06003$

22. Taplin R H 2012 Tourism Manage. 33 29-37

23. Oh H 2001 Tourism Manage. 22 617-627

24. P.T. Kereta Commuter Indonesia, available at http://www.krl.co.id/ (Accessed on April 17 2018)

25. Cronbach L J 1951 Psychometrika 16 297-334

26. Nagpal J, Kumar A, Kakar S and Bhartia A 2010 J. Assoc. Phys. India 58 295-304

27. Chen K Y 2014 Tourism Manage. 40 260-272

28. Ulkhaq M M, Putra B E, Arianie G P, Amalia A N and Pramono S N W 2016 J. Econ. Bus. Manage. 4 538-545 